\title{
A CASE OF
}

\section{STRICTURE OF THE TRACHEA.}

\author{
Br W. C. WORThiNGTON, Esq., \\ SENIOR SURGEON TO THE LOWESTOFT INFIRMARY. \\ Сommunicated by JAMES COPLAND, M.D., F.R.S., \&c.
}

READ JANUARY 11Th, 1842.

Charles Newrick, aged 49, an agricultural labourer, of spare habit of body, first came under my notice in August 1837. During the early part of his life, he had enjoyed tolerably good health, with the exception of occasionally suffering from slight cough, which was sometimes increased by the employment of thrashing, owing to the dust rising from the corn, and irritating the fauces and respiratory passages. In 1833 he contracted syphilis, for the cure of which, mercury had been administered, but not to an immoderate extent. At this time he experienced an increase of cough, and soreness about the throat, attended by slight difficulty of swallowing. His general health also began to decline, as denoted by occasional feverishness, impaired appetite and loss of flesh. These symptoms progressively and steadily advanced until the time of my first seeing him, (August 1837,) when I found him suffering from the following symptoms : 
During the last twelve months he had been confined to the house; he was much emaciated, was very feeble, and complained of want of appetite, and of uneasiness about the throat. His state of breathing more particularly arrested my attention, as regarded both the peculiarity of the noise attendant upon inspiration, and the very painful effort required for its accomplishment. In the ordinary act of inspiring, a sound was produced, exactly resembling that produced by an unsound horse, called a roarer or whistler, and this sound at once suggested the idea, that, in the act of inspiring, the air passed through a tube of preternaturally small diameter. Each inspiration occupied ten seconds, the chest expanding only six times in a minute. Expiration was performed in much less time than inspiration, with much less exertion and with diminished intensity of roaring. Upon examining the muscles of the throat and neck, I was forcibly struck with their violent action, more particularly with that of the sterno-hyoidei and sterno-thyroidei muscles, together with the thyro- and omo-hyoidei and other muscles of the larynx, whilst the trapezii, intercostales and diaphragm were comparatively much less acted upon. From this circumstance, aided by the other symptoms, I could not fail of concluding, that the impediment to the free passage of air into the lungs existed within the trachea or larynx, but I could not satisfactorily determine as to which of the two was principally affected. Vocalisation was very imperfect, the sound of utterance being hoarse and rough. A 
troublesome cough was present, accompanied with a copious muco-purulent expectoration, the checking of which tended, in some degree, to increase the difficulty of breathing. The patient complained also of an offensive discharge from the nostrils, followed by occasional exfoliation of osseous matter, which appeared to be connected with disease of the inferior turbinated bones. The pulse was small, quick and irritable, but no well-defined symptoms of hectic fever had yet supervened. The larynx, when moderately compressed, did not evince pain and it was only when an increased force was used that uneasiness was occasioned. The mouth and fauces did not present any marks of disease, either of the tonsils, uvula or palate, nor did these parts appear to have been the seat of previous ulceration. A slight roughness of the epiglottis was detected by the finger, but the stethoscope applied over the chest furnished no indication of disease of the lungs.

I was convinced that little or nothing beyond a palliative treatment was applicable to this man, and I ordered him a light nutritious diet. I prescribed some sedative and expectorant medicine, placed him as an out-patient of the infirmary, and occasionally visited him. Towards the autumn of the same year, $(1837$,$) he so far regained strength as to walk into$ the air and to present himself at the infirmary, and he continued to do so, occasionally, for nearly four years, in the course of which time his local symptoms did not vary much. The peculiar roaring sound never left him, nor the abnormal state of his voice, 
both symptoms maintaining the same character as when I first saw him. He was generally worse when the atmosphere was damp and cold, and when exposed to the night air. In the winter months he was mostly confined to the house, but as the weather became warmer, he could, if allowed to take his own time, walk about three or four miles in the day. Whatever promoted expectoration, usually produced a temporary relief of the dyspnœa. He described the expectorated matter as having sometimes assumed an arborescent appearance. His death took place the 15th March 1841. The whole of the week preceding the event, he had been as well as usual. On the morning of the day of his death, whilst taking some bread and milk for breakfast, some particles of this food fell into the larynx, and he was suffocated in less than five minutes.

Autopsy twenty hours after death.-The muscles of the anterior aspect of the neck were found unusually developed, their fibres being of a deep red colour, and offering a degree of rigidity when cut into, not commonly met with in that situation, and in a subject so slender and emaciated as he was. This development of these muscles manifestly proceeded from the increased action they had performed for a considerable period before death, in overcoming the impediment to the passage of air through the trachea. The lungs were moderately distended, were crepitous, and free from emphysema. The bronchial tubes were filled with a viscid mucus, but in no respect 
morbidly dilated. The glands situated about their roots were enlarged, and one of them particularly, just at the bifurcation of the trachea, was found to contain calcareous deposit, but did not appear to have produced any undue pressure upon the parts around it. The heart was smaller than is usually met with in adults, and the pericardium contained about two ounces of serum.

The trachea was detached just below its division, and removed, together with the larynx, for the purpose of close inspection. Having deprived them of their surrounding tissue, a singularly well-defined constriction, constituting complete stricture, was discovered just below the cricoid cartilage, the calibre of the strictured portion not exceeding that of a crow-quill, and at once disclosing the principal cause of the distressing symptoms during life. This partial obliteration of the canal was independent of any adventitious membrane, the product of either acute or chronic inflammatory action, as in croupy affections, and of the existence of any of the usual marks of inflammation. The tracheal rings, at the point of stricture, had entirely disappeared, and had been converted into a fibro-cellular tissue, whilst those below the constriction were much dilated beyond their natural circumference, and had also to a certain extent lost their elastic and cartilaginous character. The larynx, when held perpendicularly, presented a more flattened appearance than natural, owing to the approximation of the alæ of the thyroid cartilage. This altered shape may probably be re- 
garded as a consequence of the stricture in the trachea, and it no doubt in some degree added to the difficulty of breathing. The epiglottis showed marks of having been attacked with ulceration at some former period; the only vestiges of it remaining were two or three small irregular vegetations. The lining membrane within the larynx was slightly thickened, pale, and rather thickly smeared with a viscid muco-puriform fluid, but it presented no appearance of ever having been the seat of ulceration.

It is extremely probable that the tracheal disease had a syphilitic origin; and that the absorption of the cartilaginous rings of the treachea in the seat of stricture had caused the constriction, the contractility of the circular or transverse fibres of the membranous portion of the trachea having been no longer antagonised by these cartilaginous rings. This seems an obvious solution of the production of the organic lesion displayed in this case, which illustrates several points in the mechanism and physiology of the respiratory passages. I have never met with, nor read of, a similar case to the present : and my friend $\mathrm{Dr}$. Copland, when lately in this part of the country, informed me that he was not acquainted with any instance on record, in which the same changes as the above had been observed upon dissection.

\section{Note by Dr. Copland.}

By the permission of Mr. Worthington, the trachea, sent by him with his paper to the Society, vOL. XXv. 
was slit open in the middle of the membranous portion by Mr. Shaw.* Its inner surface presented superficial cicatrices extending both below and above the strictured portion. The cicatrized surface was smooth, although somewhat irregular, and of a serous or polished appearance; showing that the ulceration had healed long previously to death. The cartilaginous rings of the trachea were entirely absorbed from about half an inch below the thyroid cartilage downwards to the extent of about three inches. The upper part of the trachea, that had thus lost the antagonising power to the transverse fibrous structure, was constricted so as to admit only a crow-quill. The inner surface of the constricted part was quite smooth. The larynx was sound; but the inner surface of its base and the commencement of the trachea presented superficial, slight and old cicatrices. The trachea was much dilated from a little below the strictured part, to the bifurcation, and its internal surface presented the superficial cicatrices already mentioned.

* Plate IV. represents the trachea slit open. 


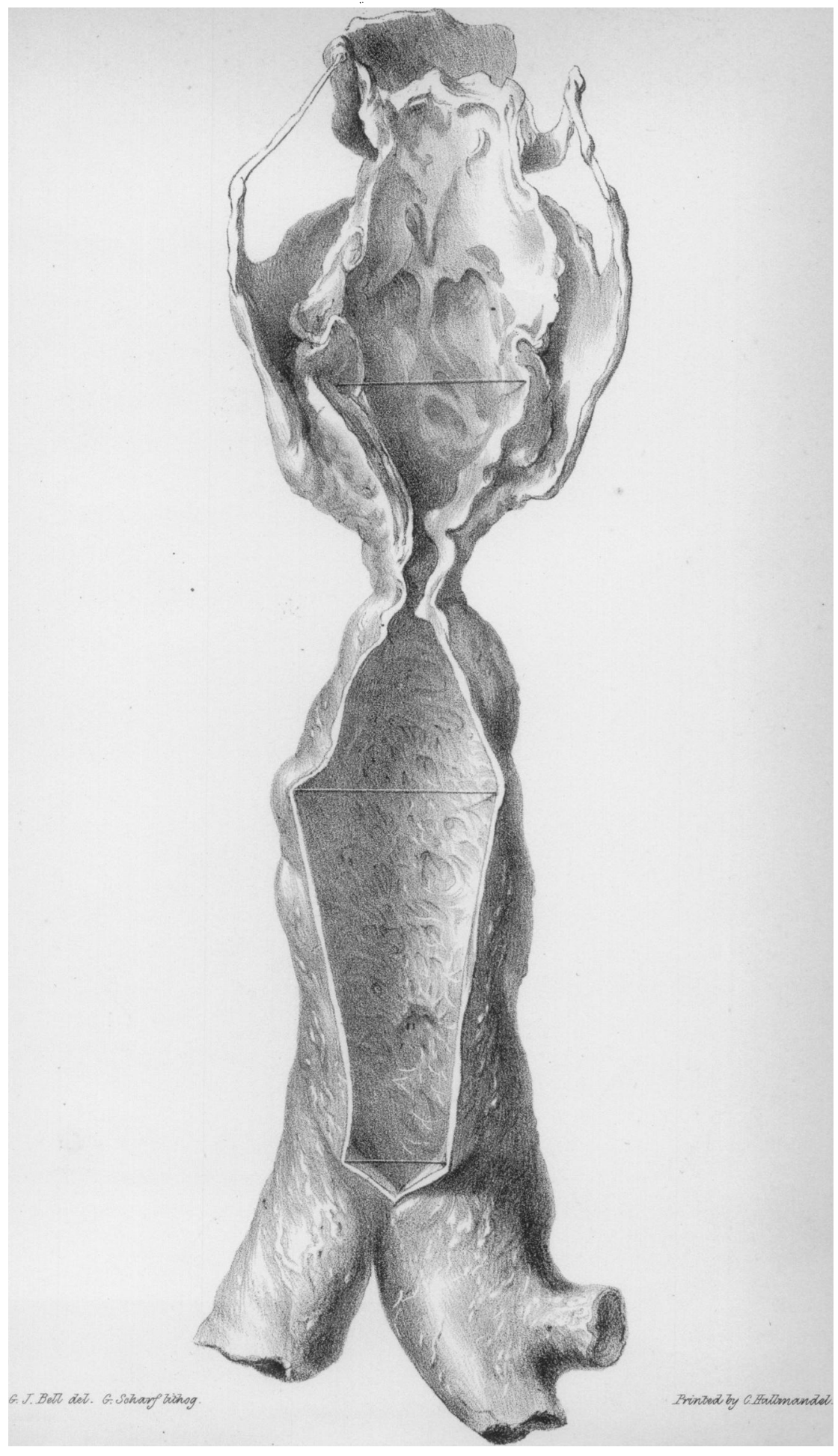

